\section{Migration and maternal health: experiences of brazilian women in Portugal}

\section{Migração e saúde materna: experiências da mulher brasileira em Portugal}

\section{Abstract}

Objectives: to characterize maternal and neonatal healthcare provided to Brazilian population, assessing key factors: access, use and quality of care received during this period. The goal was to assess possible differences regarding women's perceptions regarding the quality and appropriateness of care received, providing qualitative information, as part of a holistic perspective.

Methods: the present study adopted a qualitative methodology (semi-structured interviews) for collecting and analyzing data. Possible differences in women's perceptions regarding the quality and appropriateness of care received were assessed, providing qualitative information, as part of a holistic perspective. The present study was based on privileged information obtained from Brazilian women, residing in the metropolitan area of Porto, regardless of their legal status.

Results: a certain dissatisfaction emerged among Brazilian women regarding the quality of information provided by health professionals, the communications skills of these professionals, in addition to a perception of reduced access to medical specialties, especially in primary care. Misinformation about legal rights and inappropriate clarification during medical appointments were frequently reported and interacted with social determinants to result in poorer medical care.

Conclusions: special attention should be given to the specific needs and understanding of immigrants during pregnancy and motherhood in order to improve healthcare. New challenges tend to lie not only in ensuring access, but mostly in promoting equity, as away of providing high-quality care for all. Key words Brazilian immigrants, Care, Maternal and child health
Lígia Moreira Almeida 1

José Peixoto Caldas 2
${ }^{1}$ Institute of Public Health. Faculty of Medicine. University of Porto (ISPUP/FMUP) Rua das Taipas, 135. CEP: 40.50-600. Porto, Portugal. E-mail: ligia_almeida@fpce.up.pt

2 Centre for Research and Intervention in Education. Faculty of Psychology and Educational Sciences (CIIE/FPCEUP). University of Porto. Porto, Portugal.

\section{Resumo}

Objetivos: caracterizar a saúde materna $e$ neonatal da população brasileira, avaliando fatores fundamentais: acesso, utilização e qualidade dos cuidados recebidos durante este período. Avaliar possiveis diferenças na percepção das mulheres sobre qualidade e adequação do atendimento recebido, providenciando informações qualitativas, uma perspectiva holística.

Métodos: a presente pesquisa seguiu uma metodologia qualitativa (entrevistas semiestruturadas) para coleta e análise de dados. Avaliou-se possíveis diferenças na perceção das mulheres sobre qualidade e adequação do atendimento recebido, providenciando informações qualitativas, para uma perspetiva holística. Este estudo resultou da recolha de informações privilegiadas, obtidas de mulheres brasileiras, independentemente da situação documental, residentes na área metropolitana do Porto.

Resultados: certa insatisfação surgiu entre as mulheres brasileiras em relação à qualidade das informações fornecidas pelos profissionais de saúde, à capacidade de comunicação destes profissionais, além da perceção de um acesso reduzido às especialidades médicas, nomeadamente na atenção primária. Desinformação sobre os direitos legais e esclarecimento inadequado durante consultas médicas foram frequentemente relatados e interagiram com determinantes sociais, resultando em pior atendimento médico.

Conclusões: especial atenção deve ser prestada às necessidades especificas e compreensão das imigrantes durante a gravidez e maternidade, a fim de melhorar a saúde. Novos desafios tendem a residir não só em assegurar o acesso, mas principalmente na promoção da equidade, proporcionando qualidade dos cuidados de saúde para todos.

Palavras-chave Imigrantes brasileiras, Cuidados, Saúde materno-infantil 


\section{Introduction}

Migration presents compelling development opportunities for the European Union, given the specific needs of the labor market, essential to the maintenance (reconfiguration?) of their social structure, and the resumption of economic and cultural development. In Portugal, in recent years, the census shows that migration has played an important role in countering the aging population (declining birth rate among native Portuguese women, with migrants contributing most to the maintenance of fertility rates, fertility and births). 1,2

One of the greatest challenges posed by migration concerns the provision of universal and equitable healthcare, core accessibility and quality of services, regardless of gender, ethnicity or country of origin - healthcare as a universal right. 3,4 Health and guaranteed access to healthcare are cornerstones of social inclusion of immigrants, consisting of the main routes of entry into participatory citizenship and civil rights. 5,6 The most recent migration flows (preceding the global economic crisis, as there are no updated data other than the purely empirical framework of contemporary reality) demonstrate the feminization of migration and the increasing participation of women migrants in European demography. $5,7,8$

Scientific evidence shows that immigrant populations have a higher risk of contracting diseases such as cardiovascular disease, showing higher rates of diabetes and mortality associated with cancer when compared with native populations. 9 Migrants also have a higher risk of contracting infectious diseases such as tuberculosis, HIV / AIDS and hepatitis.4,10,11 They also show a higher risk of suffering from mental illness, including depression, schizophrenia and post-traumatic stress as a result of the interaction of specific psychosocial determinants. 12

Lines of contemporary research in health, developing ideas about recent trends have been recovering research methods that are intermittently developed as strategies or abandoned (such as social epidemiology) and attribute an important role to the social aspects and experiences of illness. There is thus an urgent need to consider the contexts in which migrants live and move about in host countries in order to understand health behaviors, the specific cultural beliefs and the accompanying demand for services and the course of diseases, by designing health policy in the context where it develops, taking account of the role of poverty, socioeconomic status and education in determining the health status and promoting understanding of a number of epidemiological phenomena which suggest extremely useful lines of research in public health. ${ }^{13-15}$

The equation relating individual and collective health is complex, multivariable and multimodal. Biochemical physical health must be seen within an entire sociological background with contextual variables associated with social, cultural and educational factors, but also with the world of the individual psychological experience of migration, the migration process of experimentation and the resulting personal challenges. It is thus impossible to conceive of health without considering personal characteristics such as resilience, tolerance of frustration and stress management in a context that is frequently one of isolation and lack of social support. International investigators have begun to look into the effects of racial stress on African women from different generations of migrants, identifying it as one of the causal factors lying behind the high rates of premature birth. 16,17 Chronic stress can interfere with and adversely affect the functioning of the immune and hormonal system, exacerbating inflammatory functions and reducing the efficiency of the metabolism. ${ }^{17,18}$

Psychosocial and social factors often result in increased vulnerability during pregnancy (psychopathological complications before and/or after birth - postnatal depression, psychosis and depression 10,12 - exacerbated by stressors associated with migration), and mother and child health should therefore receive particular attention.12,19 In a preliminary exploration of the general health indicators available for the characterization of migrant populations, it appears that this sector has tended to experience more sexual and reproductive complications; pregnancy outcomes in this group tend to be less favorable (a higher incidence of preterm babies with low weight at birth), more maternal, neonatal and child health problems, more miscarriages, a higher incidence of postpartum depression, poor gynecological follow-up and inadequate prenatal education.

Finally, to contextualize the present study, it is imperative to provide basic information on the operationalization of the National Health System and a better understanding of the potential challenges that migrants (and Portuguese nationals) often face in accessing services. The Portuguese concept of primary health care is defined as the provision of essential services, free and accessible to all. It generally consists of local services, and establishes the first contact of the individual with the required public health system (except for emergencies and 
acute health conditions that require rapid specialized intervention, in which cases, individuals have a number of network devices, including immediate transport to the hospital emergency room, to which they can also admit themselves). Health centers are the main primary care facilities. To improve the service provided by general practitioners, family physicians can also be called, when in need of health care. Despite these recommendations, a family doctor is not necessarily assigned to each patient or Portuguese migrant and, in this case, patients have to resort to medical resources. Specialized consultations must be requested from the family doctor and depend on their approval and referral to a level of secondary care (specialist consultations in pediatrics, gynecology, psychiatry, psychology, etc). Health centers also take action to promote health, prevention, immunization, curative care and rehabilitation by way of nursing teams. Surveillance of pregnancy is performed primarily by primary health services. 20

The aim of the present study is to investigate possible differences regarding native Portuguese and immigrant women's perceptions of the quality and appropriateness of care received, providing qualitative information as a way of ascertaining whether there are inequities in access to maternal health care, considering all the social players in this context. Another aim is to provide essential tools for best practices in the field of maternal healthcare and promote the development of a multi-method needs assessment of health in this population.

\section{Methods}

This study is the result of a research project funded by the FCT: "Health and Citizenship: Disparities and intercultural needs in health care for immigrant mothers" (Ref: PTDC/CS-SOC/113384/2009). The core of this research is the study and observation of "health and citizenship" and its determinants, with special regard to the health of pregnant immigrant women and access to mother and child healthcare as a key component of civil rights in Portugal.

The main participants in this project are new mothers, immigrants and Portuguese nationals living in the metropolitan area of Porto. The immigrants are children of foreign parents and were born outside the country. We highlighted and analyzed the statements and experiences of women from Brazil, to whom we provided an overall explanation of the study and its aims and from whom we obtained authorization to conduct audio recordings of the interviews, compliance and interest in participating this research, and terms of informed consent were signed. The study was approved by the governing boards and the Ethics Committees of all institutions involved.

The sample was intentional. Participants were recruited between November 2011 and February 2012 if they met the following inclusion criteria: new mothers with children under the age of 36 months (covering the entire spectrum of childbearing age) residing in Porto and its metropolitan region, whose parents were not born in Portugal (in the case of migrants). All women were receiving support from civilian associations working with migrants and Portuguese nationals (NGOs) and/or from governmental institutions with the same aim. Recruitment of participants began with contacts and meetings with the Governing Boards of the institutions and associations, after they had approved the study protocol.

Semi-structured interviews were conducted (14 in all), seven to Brazilian and seven to Portuguese women, at similar stages in motherhood. Given the characteristics of the target population, semi-structured interviews was the most appropriate data collection tool, as it required only a single meeting and ensured the absolute anonymity of each participant. This was important, as some of recent mothers interviewed were undocumented. Other strategies (e.g. focus groups, in-depth interviews, unstructured interviews) would have required not only longer meetings but also possibly multiple interviews. Although other strategies would provide extremely valid and richer information, they are not always applicable and adjustable either to the time constraints of working migrants or to concerns associated with multiple contacts with illegal migrants.

Interviews took were conducted in the association or institution where the women were recruited and lasted about 25 minutes. They were conducted by a well-trained researcher with a degree in psychology. The methodology and general objectives of the study were explained to all participants. Authorization for audio recording of the interviews was requested, and informed voluntary consent was obtained. No refusals were disclosed.

Qualitative content analysis and categorization of information were used to conduct a systematic analysis of the data collected. This involved transcription of interviews and field notes. ${ }^{21}$ Once all data had been collected, a comprehensive interpretation was carried out. Initial categories were created (corresponding to the questions asked) and this later evolved into the analysis of new data (clustering of information). Some initial questions presented as guidelines included: "Have you experienced any 
issues in accessing family planning services at health centers?"; "How would you evaluate the healthcare you received during your last pregnancy surveillance? What about the healthcare provided to your new-born?"; or "Did you notice any problem in attendance and/or in the rapport established with health professionals? Please explain how, and what were the consequences (if they existed)?" Two independent investigators coded and organized data according to the categories, and the research team met several times to establish agreement on interpretations. To maintain confidentiality, socio-demographic data were entered into a coding sheet, and the name of the participant replaced by an alphanumeric code. Quotations were selected from women's dialogues that best exemplified the emerging themes.

\section{Results}

Most Brazilian women reported a medium level education (12 years: 5 in 7 women) and legal immigration status ( 6 out of 7 women, two of them by marriage). The Portuguese women also had a basic to medium level of education (9-12 years: 5 out of 6 women). Regarding length of stay, five of the seven Brazilian women had been in the country for 7 years or less.

It was possible to group the information collected into eight major themes: a) health status, b) perceptions of access and quality of care, in comparison with those in the country of origin, c) barriers to and facilitators of the use of healthcare services, d) perceived gaps in the health system and suggestions for improvement, e) mother and child healthcare (i. pregnancy and postpartum; ii. baby follow up; iii. family planning); f) strategies for managing difficulties; g) the quality and consequences of the care provided by health professionals; h) contraception - information, decision and use.

Regarding health status, with the exception of two specific situations from the past, most Brazilians reported never having experienced any serious health problem. All respondents were assessed at the time of the interview as completely healthy, showing full agreement with the so-called "healthy migrant effect". 22,23 Only a few differences were identified in relation to specific situations and epidemiological profiles, such as postpartum depression in a Portuguese woman, and one case of endometriosis and hyperthyroidism in a Brazilian woman.

Irrespective of nationality, interviewees reported regular use of the NHS during pregnancy and in the early stages of motherhood. In other situations, use was generally limited to the emergency services (especially among migrants) and special appointments, such as with pediatricians. Most women were satisfied with the healthcare services, in particular those provided during pregnancy.

Two different perspectives were found among Brazilian women: some reported a much more positive view of the healthcare system in the host country, while others claimed that it was similar in terms of the quality of public services. This seemed to be dependent on the what part of Brazil the woman came from, demonstrating the disparities in such a vast country. "In Portugal healthcare is better. Public healthcare in Brazil is still very poor." (Brazilian participant). "In Brazil it was easier to obtain an appointment with a specialist. In a health center, you have daily access to all kinds of doctors!" (Brazilian participant). Brazilian women provided a more negative evaluation of the quality of primary healthcare centers, because of the bureaucracy associated with scheduling appointments, particularly in the case of specialist care. However, they reported being as satisfied with the healthcare services in Portugal as in their country of origin, with the exception of not having access to specialist appointments in primary healthcare settings.

All women, including Portuguese nationals, mentioned the difficulty of scheduling appointments, in both primary healthcare centers and hospitals, and the waiting time for appointments as factors associated with lower quality and dehumanization of services.

Migrant women furnished varying opinions regarding potential barriers and difficulties in accessing healthcare, mostly related to idiosyncratic personal experiences. The most significant obstacles included initial unawareness of the services that the healthcare system had to offer, the previously referred difficulty in scheduling appointments, the waiting time for appointments, and a perceived indifference towards users, particularly at emergency services.

A number of cultural issues relating to the services were mostly mentioned by Brazilians: greater harshness on the part of healthcare professionals, which often triggered inhibition in providing clarifications, posing additional questions, and returning for future complications. "In Brazil, we're more comfortable with our doctors, they smile, they're kind! Here the doctors are very serious when they talk... sometimes we even feel nervous when we talk to the doctor, as he is so serious!" (Brazilian 
participant). Several Brazilian women complained about difficulties in requesting regular medical checkups, revealing differences in the preventive approach to medicine.

With regard to factors that facilitate accessibility to healthcare services, Brazilian women pointed to a number of facilitators, referring to pregnancy as a period when they received particularly good support, and the ease of geographical accessibility of the primary healthcare centre. Having one's own General Practitioner and being pregnant are widely recognized facilitators for migrants and Portuguese nationals alike. Several Brazilian women tended to identify bureaucracy and misinformation from healthcare professionals and administrative staff as the main obstacles to the initial approach to specialized care services. "No, I don't have any problem in accessing the healthcare services... I had no social security number in early pregnancy, and I went to the doctor at my primary healthcare centre. The General Practitioner made medical access a bit difficult; she said I had no right to prenatal care, since I had no social security number and did not order the routine exams that I needed. I could only get them too late..." (Brazilian participant). It is noteworthy that some Portuguese women also reported problems with the quality of care received, not identifying them as such and not being aware of its impact. "The final part of the delivery went wrong, they got things done very quickly, and when they had to remove the placenta some of it was left inside..." (Portuguese participant).

The main complaints were common to all users, regardless of nationality. These included the time spent waiting for appointments, difficulties scheduling general and specialized appointments, lack of attention from healthcare professionals, especially in hospital emergency wards, and excessive bureaucracy. Brazilian women referred predominantly to the non-availability of specialist appointments in primary healthcare, bureaucracy in scheduling appointments, difficulties in obtaining timely care in the absence of an attributed General Practitioner, insufficient duration of appointments, and insufficient clarification provided by healthcare professionals. Suggestions for improvement of services focused on the need to provide more humane care and be more interculturally aware. "Appointments don't need to be more frequent, but longer!.. More time for appointments! It's rushed!... It is a shame we cannot ask more questions!" (Brazilian participant).

We observed that pregnancy follow-up is one of the services with which users were most satisfied, being more rewarding to Portuguese women. Nevertheless, this satisfaction rarely extends to postpartum medical care, in which women (irrespective of nationality) overwhelmingly referred to a lack of social and emotional support, reporting feelings of being abandoned by the NHS. Brazilian women tended to report high satisfaction with care received during pregnancy. The difficulties they most identified involved the initial contact with the NHS, and some unfamiliarity on the part of physicians and administrative professionals regarding free access to healthcare for pregnant women, even if undocumented. This resulted in poor and late prenatal care for some Brazilian women.

With regard to medical care for infants, after being discharged from hospital, several immigrants reported difficulties in obtaining sufficiently clarifying medical consultations, mentioning a lack of pediatric specialists to pursue baby follow-up. Brazilian women reported widespread dissatisfaction with baby follow-up, when it is carried out in primary healthcare (by general practitioners), since, in their country, pediatric services are provided at this level of care. This often leads to more requests for hospital emergency services. The complaints and dissatisfaction observed thus relate more to difficulties and bureaucracy in the process of getting a specialized appointment, which women believe result in delays in providing pediatric services. "The family physician is ...well, is good, but not for children!" (Brazilian participant).

Family planning services are counseling and information services focusing on health prevention and protection against diseases (explicitly through free provision of contraception) and preparing women physically for pregnancy (e.g. planning early intake of folic acid). It was observed that not all women are aware of the potential and advantages of these services but, irrespective of nationality, the ones who used them were extremely satisfied.

Among Brazilian women, we found a certain discrepancies as to the source of their dissatisfaction, and effective complaints or practical management of obstacles encountered. Only one woman reported that she sought out information about her rights when facing a setback in accessing maternal healthcare. Some Portuguese women behaved similarly: despite being knowledgeable about the functioning of the NHS, Portuguese women of low socioeconomic status (SES) only make verbal complaints, demanding their rights (real or perceived) exclusively by way of oral protest. In very serious situations or circumstances with a high probability of medical failure, they tended not to follow up 
complaints. "The final part of the delivery went wrong. When removing the placenta, the doctors didn't completely eliminate the remains... And that made me develop an infection that forced me to stay in hospital a few days. I wasn't pleased ... but I didn't complain. "(Portuguese participant).

As noted above, Brazilian women had a very positive opinion of the healthcare received, especially during pregnancy and in terms of family planning and contraception. Yet, they tended not to identify potential sub-quality experiences, not relating them to later adverse consequences. Some experiences occurred that jeopardized the quality of services, such as obstacles posed by some health professionals (specifically in terms of the content of consultations). "Sometimes you get a doctor who is very insensitive, like... she told me (about my son): "The fever began today, why are you here? Go home and give him Ibuprofen." (Brazilian participant).

Migrants and their Portuguese counterparts cite family planning services as an example of adequate functioning, fully responding to their requirements. Most Brazilian women self-assessed themselves as having sufficient knowledge regarding methods of contraception. They tended to experiment with a wide range of contraceptives, playing an active role in the selection of the method, often resulting in better collaboration between the women and the health professional. "Whenever I need to, I turn to Health Centre, because it's free! Let's make use of it! I just call them, make an appointment, and go there to pick it up. My doctor gives me more options. But, for now, I just take the pill." (Brazilian participant). Portuguese women demonstrated similar patterns when choosing methods of contraception, also doing so in collaboration with health professionals (frequently agreeing with the professionals' suggestions). The methods used varied. "At the Maternity unit, when I had my first child, I put in the (subcutaneous) implant. When I took out the implant, I put in the vaginal ring. Now (that my baby has been born) I'll use the breastfeeding pill."(Portuguese participant).

\section{Discussion}

Brazilian women often experience difficulty in early integration (owing to both internal and external barriers), but over time and from one generation to the next, integration is usually a success. The main mechanisms identified as facilitators of this process were acquiring nationality (length of stay in Portugal), and gradual adoption of the culture and customs of the host society - developing active and increasingly adapted social participation.

Portugal has shown strong commitment to improving the integration of immigrants by way of comprehensive legislation, potentially favoring legalization and the acquisition of dual citizenship (when the home country permits) and family reunification, with comparatively broad political integration with the European Union, particularly with regard to free access to health care for pregnant women and new mothers. However, there are a number of gaps between the law and reality on the ground that contribute to systematically poorer health indicators and integration among the immigrant population, particularly Brazilians. Data was found to suggest there is a need to change the focus from access of immigrant women to healthcare (which has largely been achieved at a national level) to ensuring the quality of care, which is a trend that exists in most European countries that share the assumption that health is a universal right. $24-26$

Ongoing research has already shown that most complaints concern aspects not covered by legislation, which facilitates encroachment on the law on the part of those who receive migrants. The increasing bureaucratization associated with institutions that the Portuguese Government provides for overseeing and regulating the entry and integration of immigrants has been extremely damaging, exacerbating the difficulties and vulnerabilities arising from migration.

Our methodology enabled us to observe specific problems in the healthcare system that need to be addressed: Brazilian women expressed dissatisfaction regarding the suboptimal information provided by healthcare professionals, which some women felt to be mediated by prejudice or indifference. They also criticized the bureaucracy of primary healthcare centers and the limited access to specialized care, as they perceived it. Likewise they felt preventive care strategies to be insufficient. Another aspect perceived as a stressor by Brazilian women was the different health practices used in the country of origin. Differences in the routine use of clinical examinations and scheduling of specialist appointments often resulted in inhibiting the women from seeking further clarification and general dissatisfaction. These issues were frequently perceived as an example of health deprivation.

The social gradient in health is a crucial challenge where inequalities are deep-rooted. The present study has shown, in previous stages, that social risk is widely associated with socio-material deprivation and this tends to be reflected in social exclusion from goods and services, including health 
and education.11,27 It is therefore fundamental to consider the predominant role that poverty plays in racial disparities between health outcomes. ${ }^{28}$ Inequalities in health cannot be taken separately from education achievement, physical and psychosocial hazards at work, living conditions, employment status, job insecurity, income and other social determinants of health. Social epidemiology alerts us to this issue, as people with lower social-economic status tend to require more healthcare services. Public health policies must compensate for these inequalities by providing opportunities for good health for all. ${ }^{29}$ Proper healthcare needs to strike a balance between clinical skills and adequate commu-

\section{References}

1. Caldas J. Inmigración y salud: un nuevo reto para las políticas de salud pública. VII Jornadas de Sociología de la UBA: Pasado, presente y futuro de la sociología; UBA/IGG, Buenos Aires: Argentina; 2007.

2. Estrela J, Machado R, Bento AR, Martins LA, Sousa P Relatório de Imigração, Fronteira e Asilo 2011. Oeiras: SEF; 2012.

3. Fernandes A, Miguel J. Health and migration in the European Union: better health for all in an inclusive society. Lisboa: Instituto Nacional de Saúde Doutor Ricardo Jorge; 2009

4. Ingleby D. Ethnicity, Migration and the "Social Determinants of Health" Agenda. Psychosocial Interv. 2012; 21 (3): 331-41.

5. Dias S, Rocha C. Saúde sexual e reprodutiva de mulheres imigrantes africanas e brasileiras. Lisboa: Observatório da Imigração; 2009.

6. Dias S, Gama A, Rocha C. Immigrant women's perceptions and experiences of health care services: insights from a focus group study. J Public Health. 2010; 18: 489-96.

7. Fonseca M, Silva S, Esteves A, McGarrigle J. MIGHEALTHNET - Relatório sobre o Estado da Arte em Portugal. Lisboa: Universidade de Lisboa; 2009.

8. Martins I, Faria A, Lage G. Diversidade Cultural Urbana. Porto: Câmara Municipal do Porto; 2010.

9. Carballo M. Non-communicable Diseases. Lisboa: Instituto Nacional de Saúde Doutor Ricardo Jorge; 2009

10. Rumbold A, Bailie R, Si D, Dowden M, Kennedy C, Cox R, O’Donoghue, L, Liddle, H, Kwedza, R, Thompson, S, Burke, H, Brown, A, Weeramanthri, T, Connors, C. Delivery of maternal health care in indigenous primary care services: baseline data for an ongoing quality improvement initiative. BMC Pregnancy Childbirth [Internet]. 2011; 11: 16.

11. IOM. World Migration Report 2011: Communicating effectively about migration. Geneva: International Organization for Migration; 2011

12. Bunevicius R, Kusminskas L, Bunevicius A, Nadisauskiene R, Jureniene K, Pop V. Psychosocial risk factors for depression during pregnancy. Acta Obstet Gynecol Scand. 2009; 88: 599-605. nication strategies, and not only free access to services. Patients' perspectives are essential for assessing the quality of healthcare and should be taken into account by policy makers. 30

\section{Acknowledgments}

The authors would like to express their gratitude for the funding received from the FCT funding agency, without which the present study would not have been possible. The authors would also like to thank Catarina Casanova for her valuable contribution, especially with regard to data collection.

13. CSDH. Closing the gap in a generation: health equity through action on the social determinants of health Geneva: World Health Organization; 2008.

14. Loureiro I, Miranda N. Promover a saúde: dos fundamentos à acção. Coimbra: Edições Almedina; 2011.

15. WHO (World Health Organization). Health of migrants: the way forward: report of a global consultation. Geneva; 2010.

16. Gushulak B, Pace P, Weekers J. Migration and health of migrants. In: Europe WROf, editor. Poverty and social exclusion in the WHO European Region: health systems respond Copenhagen; 2010.

17. Harutyunyan R. Pregnant African American women face barriers to health care: US Fed News Service; 2008.

18. Schetter C. Psychological science on pregnancy: stress processes, biopsychosocial models, and emerging research issues. Ann Rev Psychol. 2011; 62: 531-58.

19. Thomsen S, HOA DTP, Malqvist M, Sanneving L, Saxena D, Tana S, Beibei Y, Byass P. Promoting equity to achieve maternal and child health. Reprod Health Matters. 2011; 19 (38): 176-82

20. Machado MC, Santana P, Carreiro MH, Nogueira H, Barroso MR, Dias A. Iguais ou diferentes? Cuidados de saúde materno-infantil a uma população de imigrantes. Laboratórios BIAL; 2006.

21. Bogdan R, Biklen S. Qualitative research for education. An introduction to theories and methods. New York: Pearson Education group; 2003.

22. Bray JK, Gorman DR, Dundas K, Sim J. Obstetric care of new European migrants in Scotland: an audit of antenatal care, obstetric outcomes and communication. Scott Med J. 2010; 55 (3): 26-31.

23. Ganann R, Sword W, Black M, Carpio B. Influence of maternal birthplace on postpartum health and health services use. J Immigr Minor Health. 2012; 14 (2): 223-9.

24. Malin M, Gissler M. Maternal care and birth outcomes among ethnic minority women in Finland. BMC Public Health. 2009; 9: 84.

25. Fedeli U, Alba N, Lisiero M, Zambon F, Avossa F, Spolaore P. Obstetric hospitalizations among Italian women, regular 
and irregular immigrants in North-Eastern Italy. Acta Obstet Gynecol Scand. 2010; 89 (11): 1432-7.

26. Dias S, Gama A, Rocha C. Immigrant women's perceptions and experiences of health care services: Insights from a focus group study. J Public Health. 2010; 18: 489-96.

27. Marmot M. Social determinants of health inequalities Lancet. 2005; 365: 1099-104.

28. Marmot M, Bell R. Improving Health: Social Determinants and Personal Choice. Am J Prev Med. 2011; 40: S73-7.
29. Eastwood JG, Phung H, B B. Postnatal depression and socio-demographic risk: Factors associated with Edinburgh Depression Scale scores in a metropolitan area of New South Wales, Australia. Australian and New Zealand. J Psychiat. 2011; 45: 1040-6.

30. Jonkers M, Richters A, Zwart J, Ory F, van Roosmalen J. Severe maternal morbidity among immigrant women in the Netherlands: patients' perspectives. Reprod Health Matters. 2011; 19 (37): 144-53.

Recebido em 14 de dezembro de 2012

Versão final apresentada em 9 de maio de 2013

Aprovado em 5 de setembro de 2013 